\title{
PAPERS
}

\section{Screening for early familial ovarian cancer with transvaginal ultrasonography and colour blood flow imaging}

\author{
Thomas H Bourne, Stuart Campbell, Karina M Reynolds, Malcolm I Whitehead, Jayne Hampson, \\ Patrick Royston, Timothy J B Crayford, William P Collins
}

\begin{abstract}
Objective-To assess the value of transvaginal ultrasonography with colour blood flow imaging in detecting early ovarian cancer in women with a family history of the disease.

Design-Study of self referred symptomless women with a close relative who had developed the disease. Each woman was screened to detect persistent lesions and defined changes in ovarian volume. Morphological score and pulsatility index were recorded.
\end{abstract}

Setting-Ovarian screening clinic.

Subjects-1601 self referred women.

Interventions-Women with a positive screening result were recommended to have further investigations.

Main outcome measures-Findings at surgery and histology of abnormal ovaries. Morphological score $\geqslant 5$ and pulsatility index $<1 \cdot 0$ at last scan.

Results-Women were aged 17 to 79 (mean 47) years; $959(60 \%)$ were premenopausal, $469(29 \%)$ were naturally postmenopausal, and $173(11 \%)$ had had a hysterectomy. 157 women had a pedigree suggestive of the site specific ovarian cancer syndrome and 288 of multiple site cancers. 61 women had a positive screening result $(3 \cdot 8 \%, 95 \%$ confidence interval 2.9 to $4.9 \%$ ), six of whom had primary ovarian cancer detected at surgery (five stage Ia, one stage III). Use of a high morphological score or a low pulsatility index increased the odds of finding ovarian cancer from $1: 9$ to about $2: 5(1: 1$ in the highest risk groups). Five interval cancers were reported (three ovarian and two peritoneal). Eight of the 11 cancers developed in women with pedigrees suggestive of inherited cancer.

Conclusions-Transvaginal ultrasonography with colour flow imaging can effectively detect early ovarian cancer in women with a family history of the disease. The screening interval should be less than two years.

\section{Introduction}

Primary ovarian cancer remains the commonest cause of death from gynaecological malignancy in the United Kingdom (about 4000 deaths a year). More than $90 \%$ of women who have the disease diagnosed will be over 44 years old, and less than $35 \%$ will survive for five years from the time of diagnosis. ${ }^{1}$ The early stages of malignant growth in the ovary do not usually produce symptoms, and late diagnosis and ineffective treatments are probably the main reasons for the poor prognosis. Despite extensive research the mortality does not seem to be decreasing. Consequently, an effective procedure is needed to detect ovarian cancer at an early stage, when the five year survival rate after surgery alone can be greater than $90 \%{ }^{2}$
Transabdominal ultrasonography provided valuable information about the requirements of a screening procedure for early ovarian cancer in women without symptoms from the general population..$^{3-5}$ Preliminary data have been reported on the potential application of transvaginal ultrasonography for the same purpose. ${ }^{.7}$ Other studies have shown that adding transvaginal colour blood flow imaging and analysis can help distinguish between malignant and benign ovarian tumours. ${ }^{8-12}$ The low incidence of ovarian cancer in the general population means that multicentre trials are required to evaluate the potential usefulness of these techniques in screening symptomless women. However, subgroups of women with a higher incidence of the disease could be screened. ${ }^{13}$ In particular, evidence has been accumulated to show that a family history of ovarian cancer is an important risk factor. ${ }^{14}$

We screened a cohort of women who had at least one close relative who had developed ovarian cancer. The high prevalence of the disease and other ovarian lesions in the first 776 women screened has been reported. ${ }^{15}$ In addition, we analysed and classified the family histories and calculated the relative and lifetime risks of the first degree relatives developing ovarian and other types of cancer. ${ }^{1617}$ We report here an evaluation of the first stage of the screening procedure by menstrual state and pedigree, the retrospective and prospective use of a morphological score, and an index of intralesion blood flow at the time of the last scan as second stage tests.

\section{Subjects and methods}

We screened self referred, symptomless women (aged $\geqslant 25$ years), with at least one close relative (mother, sister, daughter, maternal or paternal grandmother, or aunt) who had developed ovarian cancer. Potential volunteers were made aware of the study by advertisements in the local and national press. All women who requested further information were sent details about the aims of the study, the screening procedure, and the action to be taken if an abnormality was detected. The protocol was approved by the research ethics committee of King's College Hospital. A nurse specialist constructed a pedigree from the information provided by each woman. Verification that the close relative had had ovarian cancer diagnosed was available from death certificates or pathology reports in about $60 \%$ of cases. Volunteers completed a questionnaire designed to provide epidemiological data and relevant personal medical history.

Each woman had one or more ultrasound examinations. The first 800 women were scanned sequentially with transabdominal and transvaginal probes to compare the information obtained from both approaches. Subsequently only the transvaginal route was used. A Diasonics SPA 1000 scanner (Diasonics Sonotron, Bedford) with a $3.5 \mathrm{MHz}$ transducer was
Correspondence to:

Professor Collins.

BMf 1993;306:1025-9 
used for all transabdominal examinations and an Aloka SSD 680 scanner with a $5.0 \mathrm{MHz}$ transducer (Aloka, Tokyo, Japan) for $92 \%$ of the transvaginal scans. The ovarian volumes and morphology were recorded.

The women were instructed to drink a litre of fluid one hour before being scanned transabdominally. A morphologically normal ovary gave an image with a smooth ovoid outline and a uniform low level echogenicity similar to that of the myometrium. Round, uniformly echogenic structures with a smooth outline in premenopausal women (and in young women after hysterectomy) were assumed to be normal ovarian follicles or corpora lutea. The maximum transverse $\left(D_{1}\right)$, anteroposterior $\left(D_{2}\right)$, and longitudinal $\left(D_{3}\right)$ diameters of both ovaries were measured. Ovarian volumes were estimated according to the formula volume $=(\pi / 6) \times D_{1} \times D_{2} \times D_{3}$. The women were then asked to empty their bladders before being scanned transvaginally in the lithotomy position. The probe was covered with a coupling gel, then a condom, and finally with more gel before insertion into the vagina. The ovaries were usually located next to the internal iliac vessels, which appeared as anechoic tubular structures with echogenic walls. All observations and measurements were recorded.

\section{MAIN SCREENING ALGORITHM}

The result of screening was regarded as positive if there was any sign of abnormal ovarian morphology (areas of hyperechogenicity or hypoechogenicity). ${ }^{3}$ Enlarged ovaries with no signs of abnormal morphology were regarded as normal. Women with an abnormal result on screening were rescanned after three to eight weeks to exclude transient changes in ovarian morphology or size. If the volume had reduced to less than $63 \%$ of that recorded at the initial scan (a cut off value derived from the results of a previous studys) the woman was classified as having no abnormality unless adverse morphological changes were seen in the contralateral ovary.

If the scan still showed an abnormality the woman was informed about the nature and possible significance of the findings. The information was sent to the woman's family doctor with a recommendation that she be referred to a local gynaecological oncologist or to one at King's College Hospital for further investigations, including laparotomy. Ovarian tissues removed at surgery were sent for histological examination. The stage of the disease was determined by the surgeon and the final diagnosis was based on the report from the histologist.

\section{ADDITIONAL INDICES}

At the time of the final scan the ovaries of women with a positive result on screening were also examined by transvaginal colour flow mapping for signs of vascular changes and decreased resistance to blood flow. The pulsatility index was used for analysis. A value less than 1.0 was used to indicate the possible presence of ovarian cancer, this level being derived from the results of a preliminary study of persistent or overt ovarian masses. ${ }^{8}$ The ovarian lesion was also assessed in detail and described as a simple unilocular or complex cyst (for a retrospective binomial analysis) and given a morphological score (for numerical analysis). A weighted scoring system was used based on the number of cysts (1 monocystic, 2 multicystic), the number of locules (0 unilocular, 1 multilocular), the presence of papillary projections ( 0 absent, 2 present), irregularities of outline in the worst case ( 0 regular, 2 irregular), and the echogenicity of the cyst fluid ( 0 anechoic, 1 random echogenicity, 2 uniform echogenicity). Examination of the data after screening 1000 women showed that a morphological score $\geqslant 5$ maintained a high detection rate for ovarian cancer. A low pulsatility index or a morphological score $\geqslant 5$ in a persistent lesion was used prospectively to define a positive result in the screening algorithm for the final 601 women. Peripheral blood $(10 \mathrm{ml})$ was also taken at each stage of the screening procedure to measure serum antigen concentration. This aspect of the study will be published separately.

\section{DEFINITIONS}

The women were classified as premenopausal (a menstrual period within the previous 12 months), naturally postmenopausal (age greater than 35 years and at least 12 months since the last menstrual period), or artificially postmenopausal (hysterectomy but with conservation of at least one ovary). This information was used to help identify normal growths according to the day of the menstrual cycle or age. The pedigrees were reviewed by two clinical geneticists and two of the authors (JH, WPC) and divided retrospectively into three groups: (a) site specific ovarian cancer (only ovarian cancer present in two or more first or second degree relatives in a pattern suggestive of an autosomal dominant inheritance); (b) multiple site cancer family syndrome (evidence for the dominant inheritance of more than one type of cancer excluding the lung and cervix); and (c) no clear inheritance pattern (no evidence for the dominant inheritance of ovarian or any other cancers).

\section{HISTOPATHOLOGY '}

Tissues from abnormal ovaries were examined at the referral hospitals and histology reports were sent to the ovarian screening clinic at King's College Hospital. The lesions were classified according to criteria recommended by the World Health Organisation into common epithelial tumours, sex cord stromal tumours, germ cell tumours, and tumour-like conditions. ${ }^{18}$ The tumours were also classified as benign, borderline, or malignant. The stage of each primary cancer was determined at the time of laparotomy according to the revised recommendations of the International Federation of Gynaecologists and Obstetricians. ${ }^{19}$ At stage Ia the tumour was limited to one ovary, the capsule was intact, there was no sign of tumour on the external surface of the ovary or elsewhere in the peritoneal cavity, and ascites was absent.

\section{DATABASE AND STATISTICAL ANALYSIS}

A database was established by using Foxbase on an IBM compatible microcomputer with a hard disk. Programs were developed to facilitate data entry, checking, and retrieval. Women were classified as being free of ovarian cancer if there was no sign of the disease at least 18 months after the screening. The detection rate (sensitivity) of the screening procedure was defined as the proportion of all women with primary ovarian cancer who had a positive result on screening during the study period. This criterion could be ascertained only within the limitation of the study design, because there is no independent method to detect early ovarian cancer without surgery. The false positive rate of the procedure was the percentage of women who were free of cancer but had a positive screening result. The positive predictive value was the percentage of women with a positive screening result who were found to have ovarian cancer at surgery. The same data were expressed as the odds in favour of the presence of ovarian cancer at surgery in women with a positive screening result - that is, odds=positive predictive value/(100- positive predictive value).

\section{FOLLOW UP}

We attempted to contact all women who were recruited into the study, by letter or telephone, six to 16 months after their last scan to check their health and 
ask if they would like to attend for a second screening. Replies were obtained from 1392 women (89\%). The women were also asked to inform us if they had cancer diagnosed at any time before their next screening.

\section{Results}

A total of 1601 women were screened and classified by age and menstrual state (table I). Their mean age was 47 (range 17 to 79 ) years; $1408(88 \%)$ had at least one first degree relative affected, and $193(12 \%)$ reported a second degree relative as the index case. There were about twice as many premenopausal as postmenopausal women, and $445(28 \%)$ women belonged to the highest risk groups (either multiple site cancer or site specific ovarian cancer syndrome). Many women $(692,43 \%)$ had only one ultrasound scan; the

TABLE I-Menstrual state and pedigree of women screened for ovarian cancer

\begin{tabular}{llccc}
\hline & $\begin{array}{c}\text { No clear } \\
\text { inheritance } \\
\text { pattern }\end{array}$ & $\begin{array}{c}\text { Multiple } \\
\text { site } \\
\text { cancers }\end{array}$ & $\begin{array}{c}\text { Only ovarian } \\
\text { cancer }\end{array}$ & Total (\%) \\
\hline $\begin{array}{c}\text { Prementrual state } \\
\text { Artificially }\end{array}$ & 691 & 149 & 119 & $959(60)$ \\
$\begin{array}{c}\text { postmenopausal } \\
\text { Naturally }\end{array}$ & 346 & 102 & 21 & $469(29)$ \\
postmenopausal & $1156(72)$ & $288(18)$ & $157(10)$ & $1601(100)$ \\
\hline Total (\%) & 119 & 17 & $173(11)$ \\
\hline
\end{tabular}

*Women who had had a hysterectomy but conservation of at least one ovary.

TABLE II-Number of women with true positive and false positive results on screening based on histopathology by menstrual state and pedigree

\begin{tabular}{|c|c|c|c|c|c|c|c|c|}
\hline \multirow[b]{2}{*}{ Menstrual state } & \multicolumn{2}{|c|}{ No clear inheritance } & \multicolumn{2}{|c|}{ Multiple site cancer } & \multicolumn{2}{|c|}{ Only ovarian cancer } & \multicolumn{2}{|c|}{ Total } \\
\hline & $\begin{array}{c}\text { True } \\
\text { positive }\end{array}$ & $\begin{array}{c}\text { False } \\
\text { positive }\end{array}$ & $\begin{array}{c}\text { True } \\
\text { positive }\end{array}$ & $\begin{array}{c}\text { False } \\
\text { positive }\end{array}$ & $\begin{array}{c}\text { True } \\
\text { positive }\end{array}$ & $\begin{array}{c}\text { False } \\
\text { positive }\end{array}$ & $\begin{array}{c}\text { True } \\
\text { positive }\end{array}$ & $\begin{array}{c}\text { False } \\
\text { positive }\end{array}$ \\
\hline Premenopausal & 2 & 22 & 2 & 4 & 1 & 2 & 5 & 28 \\
\hline $\begin{array}{l}\text { Artificially } \\
\text { postmenopausal` }\end{array}$ & 0 & 8 & 1 & 5 & 0 & 1 & 1 & 14 \\
\hline Naturally postmenopausal & 0 & 8 & 0 & 5 & 0 & 0 & 0 & 13 \\
\hline Total & 2 & 38 & 3 & 14 & 1 & 3 & 6 & 55 \\
\hline
\end{tabular}

^Women who had had a hysterectomy but with conservation of at least one ovary.

TABLE III-Primary cancers detected by screening according to women's menstrual state and pedigree

\begin{tabular}{|c|c|c|c|c|c|}
\hline Case No & Age (years) & Menstrual state & Pedigree & Histological classification & Cancer stage $^{\star}$ \\
\hline 115 & 38 & Premenopause & $\begin{array}{l}\text { Only ovarian } \\
\text { cancer }\end{array}$ & Serous cystadenocarcinoma & Ia \\
\hline 330 & 63 & $\begin{array}{l}\text { Artificial } \\
\text { menopause }\end{array}$ & $\begin{array}{l}\text { Multiple site } \\
\text { cancer }\end{array}$ & $\begin{array}{l}\text { Borderline serous } \\
\text { cystadenocarcinoma }\end{array}$ & Ia \\
\hline 464 & 54 & Premenopause & No inheritance & $\begin{array}{l}\text { Endometrioid } \\
\text { cystadenocarcinoma }\end{array}$ & Ia \\
\hline 1058 & 46 & Premenopause & No inheritance & $\begin{array}{l}\text { Borderline endometrioid } \\
\text { cystadenocarcinoma }\end{array}$ & Ia \\
\hline 1375 & 46 & Premenopause & $\begin{array}{l}\text { Multiple site } \\
\text { cancer }\end{array}$ & Serous cystadenocarcinoma & III \\
\hline 1378 & 30 & Premenopause & $\begin{array}{l}\text { Multiple site } \\
\text { cancer }\end{array}$ & $\begin{array}{l}\text { Borderline serous } \\
\text { cystadenocarcinoma }\end{array}$ & Ia \\
\hline
\end{tabular}

^According to recommendations of the International Federation of Gynaecologists and Obstetricians.

TABLE IV-Cancers reported at follow up by menstrual state and pedigree

\begin{tabular}{|c|c|c|c|c|c|c|}
\hline Case No & Age (years) & Menstrual state & Pedigree & $\begin{array}{l}\text { Histological } \\
\text { classification }\end{array}$ & $\begin{array}{l}\text { Cancer } \\
\text { stage }^{\star}\end{array}$ & $\begin{array}{l}\text { Time from last } \\
\text { scan (months) }\end{array}$ \\
\hline 54 & 43 & Premenopause & $\begin{array}{l}\text { Multiple site } \\
\text { cancer }\end{array}$ & $\begin{array}{l}\text { Endometrioid } \\
\text { cystadenocarcinoma }\end{array}$ & $\mathrm{IIb}$ & 44 \\
\hline 170 & 37 & Premenopause & $\begin{array}{l}\text { Multiple site } \\
\text { cancer }\end{array}$ & $\begin{array}{l}\text { Serous } \\
\text { cystadenocarcinoma }\end{array}$ & III & 41 \\
\hline 220 & 55 & Postmenopause & $\begin{array}{l}\text { Multiple site } \\
\text { cancer }\end{array}$ & $\begin{array}{l}\text { Peritoneal } \\
\text { adenocarcinoma }\end{array}$ & & 8 \\
\hline 452 & 53 & Premenopause & $\begin{array}{l}\text { Multiple site } \\
\text { cancer }\end{array}$ & $\begin{array}{l}\text { Serous } \\
\text { cystadenocarcinoma }\end{array}$ & III & 24 \\
\hline 1240 & 54 & Premenopause & No inheritance & $\begin{array}{l}\text { Peritoneal } \\
\text { adenocarcinoma }\end{array}$ & & 2 \\
\hline
\end{tabular}

*According to the recommendations of the International Federation of Gynaecologists and Obstetricians. remainder had two to nine scans. The same women had positive screening results with transabdominal and transvaginal ultrasonography.

OUTCOME OF SCREENING

Table II shows the numbers of true and false positive results by the women's menstrual state and pedigree. Overall $3 \cdot 8 \%(61 / 1601)$ of women had a positive screening result and were referred for surgical investigation: $8 \cdot 7 \%(15 / 173)$ in the artificially postmenopausal group, $3.4 \%(33 / 959)$ in the premenopausal group, and $2 \cdot 8 \%$ $(13 / 469)$ in the postmenopausal group. No ovarian abnormalities were observed in four women at laparoscopy, and 57 had laparotomy and bilateral oophorectomy.

Six primary ovarian cancers were detected (prevalence $0.37 \%$ ). Five cancers developed in premenopausal women (aged 30-54 years), five were stage Ia, and three were classified as borderline (table III). Four occurred in women with the highest risk pedigrees. Of the 55 women with false positive results, 25 had a tumour-like condition, 23 had a benign tumour, and seven had no abnormality detected at laparoscopy or after laparotomy.

The screening procedure had an apparent detection rate of $100 \%$ (within the limitation of the study design and our knowledge of the disease) with an overall false positive rate of $3 \cdot 4 \%(55 / 1595,95 \%$ confidence interval $2.6 \%$ to $4.5 \%$ ). The denominator is the total number of women minus the number of true positive results. The false positive rate was $2.9 \%(28 / 954,2 \cdot 0 \%$ to $4 \cdot 2 \%)$ for premenopausal women, $8 \cdot 1 \%(14 / 172,4 \cdot 5 \%$ to $13 \cdot 3 \%)$ for artificially postmenopausal women and $2 \cdot 8 \%$ $(13 / 469,1.5 \%$ to $4 \cdot 7 \%)$ for postmenopausal women. The odds of a woman with a positive screening result having an ovarian mass (by histological classification) were about 8:1 (eight women with at least one mass per nine laparotomies or laparoscopies). The odds for the presence of any ovarian tumour (as opposed to persistent tumour-like conditions) at surgery fell to about $1: 1 \cdot 7$. The odds for the detection of primary ovarian cancer at the first stage of the screening procedure (from subsequent histological and follow up data) were about $1: 9$ giving a probability of 1 in 10 .

FOLLOW UP

Up to January 1993 five interval cancers had been reported: three ovarian cancers diagnosed 24 to 44 months after the last scan and two peritoneal cancers diagnosed two and eight months after the last scan (table IV). Both ovaries of the two patients with peritoneal adenocarcinoma were apparently normal (as observed by transvaginal ultrasonography and at surgery). Overall, there were 11 cancers among 1601 women studied-that is, one cancer per 146 women over 4 years. Six of the cancers were classified as serous cystadenocarcinomas, three as endometrioid cystadenocarcinomas, and two as peritoneal adenocarcinomas. Eight $(73 \%)$ of the cancers developed in women with pedigrees classified as multiple site cancer or site specific ovarian cancer. Six women had prophylactic oophorectomy on the advice of THB, and a further 16 stated that they wished to withdraw from the study after one screening.

\section{USE OF ADDITIONAL VARIABLES}

If only complex persistent cysts, as determined by transvaginal ultrasonography at the last scan, were considered to be potentially malignant, all the cancers would have been detected and the number of false positive results would have been reduced by $40 \%$ from 55 to 33. Accordingly, the odds of finding ovarian cancer at surgery would have been increased to about $1: 6$. Table $\mathrm{V}$ shows the effect of retrospectively applying the morphological score $\geqslant 5$ as an index of 
cancer on the number of true and false positive screening results. One cancer would have been missed (case number 1378), but the number of false positive results would have been reduced by $89 \%$ from 55 to six. There was only one false positive result in the 469 women who were naturally postmenopausal. The odds of finding ovarian cancer at surgery would have been about $1: 1$ with a detection rate of $83 \%(5 / 6)$.

Table $\mathrm{V}$ also shows the effect of retrospectively using a pulsatility index $<1.0$ in the persistent ovarian lesion as an index of cancer. Unfortunately the equipment was not available to study the first cancer detected (case 115). One early borderline cancer would have been missed (case 330) and the false positive rate would have been reduced by $76 \%$ from 55 to 13 . Twelve of the false positive results would have occurred in women who were less than 53 years old. There was only one false positive result among postmenopausal women-in a 72 year old woman with a sex cord stromal tumour. Five women with a false positive result had endometriosis, two had teratomas, two had serous cystadenomas, and three had tumour-like conditions.

If the screening algorithm had required that the persistent ovarian lesion must have a morphological score $\geqslant 5$ and a pulsatility index $<1.0$ before the result was reported as positive then two of the five cancers would have been missed. The number of false positive results, however, would have been reduced to three (giving odds of 1:1 for finding ovarian cancer at surgery). Use of either a morphological score $\geqslant 5$ or a pulsatility index $<1.0$ as an indicator of cancer would have detected all six cancers and given 15 false positive results with odds of 2:5 (table V). The odds for the women at most risk (those with the pedigrees multiple site cancer and site specific ovarian cancer) would have been $1: 1$.

A summary of the effect of screening for familial ovarian cancer on the basis of the presence of an ovarian lesion, a defined volume change at rescan, and a high morphological score $(\geqslant 5)$ or a low intralesion pulsatility index $(<1 \cdot 0)$ is shown in Table VI. The false positive rate would be $0.94 \%$ (95\% confidence interval $0.53 \%$ to $1.54 \%$ ) and the positive predictive value $29 \%$ $(11 \%$ to $52 \%)$. After the first 1000 cases the criterion morphological score $\geqslant 5$ or pulsatility index $<1.0$ was applied prospectively in the screening algorithm. Table VII shows the number of false positive screening results with the original algorithm and after application of the two indices prospectively and retrospectively. When the criterion was applied prospectively (at the time of the ultrasound examination) the number of

TABLE V-Effect of retrospectively using a morphological score $\geqslant 5$ or pulsatility index $<1 \cdot 0$ on the number of true positive and false positive results according to menstrual state and pedigree in 1601 women

\begin{tabular}{|c|c|c|c|c|c|c|c|c|}
\hline \multirow[b]{2}{*}{ Menstrual state } & \multicolumn{2}{|c|}{ No clear inheritance } & \multicolumn{2}{|c|}{ Multiple site cancer } & \multicolumn{2}{|c|}{ Only ovarian cancer } & \multicolumn{2}{|c|}{ Total } \\
\hline & $\begin{array}{l}\text { True } \\
\text { positive }\end{array}$ & $\begin{array}{l}\text { False } \\
\text { positive }\end{array}$ & $\begin{array}{l}\text { True } \\
\text { positive }\end{array}$ & $\begin{array}{c}\text { False } \\
\text { positive }\end{array}$ & $\begin{array}{l}\text { True } \\
\text { positive }\end{array}$ & $\begin{array}{l}\text { False } \\
\text { positive }\end{array}$ & $\begin{array}{l}\text { True } \\
\text { positive }\end{array}$ & $\begin{array}{c}\text { False } \\
\text { positive }\end{array}$ \\
\hline Morphological score $\geqslant 5$ & & & & & 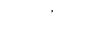 & & & \\
\hline Premenopausal & 2 & 3 & 1 & 1 & 1 & 1 & 4 & 5 \\
\hline $\begin{array}{l}\text { Artificially } \\
\text { postmenopausal }\end{array}$ & 0 & 0 & 1 & 0 & 0 & 0 & 1 & 0 \\
\hline $\begin{array}{l}\text { Naturally } \\
\text { postmenopausal }\end{array}$ & 0 & 0 & 0 & 1 & 0 & 0 & 0 & 1 \\
\hline $\begin{array}{l}\text { Puisatility index }<1 \\
\text { Premenopausal }\end{array}$ & 2 & 7 & 2 & 1 & $0^{\star}$ & 0 & $4^{\star}$ & 8 \\
\hline $\begin{array}{l}\text { Artificially } \\
\text { postmenopausal }\end{array}$ & 0 & 3 & 0 & 1 & 0 & 1 & 1 & 5 \\
\hline $\begin{array}{l}\text { Naturally } \\
\text { postmenopausal }\end{array}$ & 0 & 0 & 0 & 0 & 0 & 0 & 0 & 0 \\
\hline All & 2 & 10 & 2 & 2 & 0 & 1 & 5 & 13 \\
\hline \multicolumn{9}{|c|}{ Morphological score $\geqslant 5$ or pulsatility index $<1$} \\
\hline Premenopausal & 2 & 8 & 2 & 1 & 1 & 0 & 5 & 9 \\
\hline $\begin{array}{l}\text { Artificially } \\
\text { postmenopausal }\end{array}$ & 0 & 3 & 1 & 1 & 0 & 1 & 1 & 5 \\
\hline $\begin{array}{l}\text { Naturally } \\
\text { postmenopausal }\end{array}$ & 0 & 0 & 0 & 1 & 0 & 0 & 0 & 1 \\
\hline All & 2 & 11 & 3 & 3 & 1 & 1 & 6 & 15 \\
\hline
\end{tabular}

*One case not studied with colour flow imaging.
TABLE VI-Summary of screening results on the basis of presence of ovarian lesion, defined volume change at repeat ultrasonography and high morphological score $(\geqslant 5)$ or low pulsatility index $(<1 \cdot 0)$

\begin{tabular}{|c|c|c|c|}
\hline \multirow[b]{2}{*}{ Ovarian cancer } & \multicolumn{2}{|c|}{ Screening results } & \multirow[b]{2}{*}{ All } \\
\hline & Positive & Negative & \\
\hline $\begin{array}{l}\text { Present } \\
\text { Absent }\end{array}$ & $\begin{array}{r}6 \\
15\end{array}$ & $\begin{array}{r}0 \\
1580\end{array}$ & $\begin{array}{r}6 \\
1595\end{array}$ \\
\hline All & 21 & 1580 & 1601 \\
\hline
\end{tabular}

TABLE VII-Number of false positive results by case number after ultrasound screening and application of the criterion morphological score $\geqslant 5$ or pulsatility index $<1$ prospectively and retrospectively

\begin{tabular}{lccc}
\hline Case Nos & $\begin{array}{c}\text { Ultrasound } \\
\text { screening alone }\end{array}$ & $\begin{array}{c}\text { Criterion used } \\
\text { prospectively }\end{array}$ & $\begin{array}{c}\text { Criterion used } \\
\text { retrospectively }\end{array}$ \\
\hline $1-500$ & 25 & & 5 \\
$501-1000$ & 24 & 6 & 5 \\
$1001-1601$ & & 6 & 5 \\
\hline
\end{tabular}

false positive cases was only one higher than when it was used retrospectively (for statistical analysis). The odds of finding ovarian cancer by the new algorithm were about $1: 2$.

\section{Discussion}

We have reported previously that the prevalence of ovarian cancer detected in an ultrasound based screening programme is higher in self referred symptomless women who have at least one close relative with ovarian cancer compared with that in the general population. Moreover, an analysis of the first stage of the screening procedure and the ovarian lesions obtained at surgery showed that the proportion of women with bilateral masses and mixed disease within the same ovary was significantly higher in this subgroup than in women from the general population undergoing their first screening. ${ }^{15}$ Although the false positive rate of the screening procedure was higher $(5 \cdot 2 \%)$, the odds of finding ovarian cancer at surgery were increased from $1: 50$ in the general population to $1: 12$ owing to the higher prevalence of the disease. Subsequently we analysed and classified the pedigrees and reported that the odds of finding cancer in the women at most risk were increased even further to about $1: 5 .^{20}$

The results presented here confirm and extend our preliminary observations ${ }^{15221}$ and additionally show (both retrospectively and prospectively) how additional indices can be used to maintain the detection rate of primary ovarian cancers while reducing the false positive rate to low levels. Nevertheless, the analysis was based on the detection of a small number of cancers, and the threshold values for the new indices are preliminary. Prospective use of the new indices in the last 500 women produced an overall reduction in the number of women with a positive screening result (from $5 \cdot 2 \%$ to $3 \cdot 8 \%$ ) and an increase in the odds of finding ovarian cancer at surgery (from 1:12 to 1:9). Transvaginal, rather than transabdominal, ultrasonography enabled a more detailed assessment of each ovarian lesion. ${ }^{22}$ The analysis based on the initial classification of each lesion as a simple unilocular (not likely to be cancer) or a complex cyst (possibly cancer) showed that the odds of finding ovarian cancer at surgery could be increased to about 1:6 without reducing the detection rate. This value is similar to that obtained from the retrospective application of an intralesion pulsatility index $<1.0$ as an index of cancer. Previous studies using a morphological score to differentiate between benign and malignant overt ovarian masses have indicated that this approach might be useful in a screening programme for early ovarian 
cancer. ${ }^{23}{ }^{24}$ With our scoring system the odds of finding ovarian cancer were about $1: 1$ but one of the cancers would have been missed.

We believe that a screening procedure for ovarian cancer should have a high sensitivity (detection rate) for early stages of the disease. Our use of a high morphological score or a low pulsatility index maintained the detection rate and increased the odds of finding ovarian cancer at surgery to about $2: 5$ (or $1: 1$ in the highest risk groups). If both the morphological score and the pulsatility index had been required to be abnormal two out of five cancers would have been missed. It is particularly reassuring that the use of a morphological score or the intralesion pulsatility index gave good results when used prospectively for the last 601 women screened (three cancers were detected and there were six false positive results-three endometriosis, two serous cystadenomas, one sex cord stromal tumour). The screening algorithm has been described in more detail. ${ }^{25}$

\section{INHERITED RISK}

Most of the women reported that a first degree rather than a second degree relative had developed ovarian cancer: $66 \%$ reported cancer in their mother and $20 \%$ in a sister. The number of ovarian cancers detected in our study suggests that women with a family history of the disease are at a $9 \cdot 5$-fold increased risk of developing ovarian cancer themselves. This value is about twice as high as the risk for first degree relatives calculated from an analysis of the pedigrees. ${ }^{16} 17$ The difference may reflect the detection of some slower growing, less lethal tumours (such as the three borderline tumours) by the screening programme. The fact that five interval cancers were reported, however, suggest that women in this cohort are at very high risk of developing ovarian cancer. Only 16 women $(1 \%)$ reported at follow up that they would wish to withdraw from the study if the screening programme continued-mainly because they now have access to local facilities.

We have detected only two histological types of ovarian cancer (serous cystadenocarcinoma and endometrioid cystadenocarcinoma), and most cancers $(73 \%)$ developed in women with pedigrees suggestive of the multiple site cancer or site specific ovarian cancer syndromes. The report of two peritoneal cancers is consistent with the suggestion that the same gene or genes predispose to cancer in other epithelial cells and poses an additional problem for early diagnosis and treatment.

No data are currently available to suggest that screening for early ovarian cancer will improve survival rates and reduce mortality from the disease. We believe, however, that young women with a family history of ovarian cancer are sufficiently at risk to justify regular screening by ultrasonography as an alternative to prophylactic oophorectomy. Our data cannot easily be extrapolated to the general population. The lower prevalence of the disease might be offset by the extremely low false positive rate when the screening procedure is applied to postmenopausal women. A randomised controlled clinical trial is needed to evaluate the effectiveness of the screening procedure. Nevertheless, the lack of progress towards improving the survival rate of women with advanced ovarian cancer makes early detection and treatment desirable. Transvaginal ultrasonography with colour flow imaging has the additional advantages that it can be used to detect other pelvic malignancies such as endometrial, ${ }^{26}$ tubal, and bladder cancers and that a cervical smear can be taken when the woman is positioned for the scan. The screening service could be located alongside existing mammography units so that capital and salary costs could be shared.
This study was undertaken under the auspices of the Imperial Cancer Research Fund (ICRF). We thank previous colleagues for their contribution to the database, Mrs Janet Barton for secretarial help in the screening clinic, J Slack and $\mathrm{R}$ Houlston from the Royal Free Hospital for analysis of pedigrees, and Aloka, Tokyo, Japan, and Keymed, Southend on Sea, for the use of equipment. MIW, KMR, and TJBC were supported by the ICRF, THB and JH by the Cancer Research Campaign. The manuscript was typed by Mrs Jill Monk.

ADDENDUM-Since the manuscript was submitted one more cancer (a serous cystadenocarcinoma, stage IIa) has been detected in a 38 year old woman at the third screening. Another woman (aged 66 years) with a positive result at her second screening is still being investigated. Her ovaries appeared normal at laparoscopy, but cells were recovered from peritoneal fluid which were consistent with the presence of an adenocarcinoma.

1 Petterson F, ed. Annual report on the results of treatment in gynecological cancer. Int f Gynecol Obstet 1991;36 (suppl):238-77.

2 Young RC, Walton LA, Ellenberg SS, Homesley HD, Wilbanks GD, Decker DG, et al. Adjuvant therapy in stage I and stage II epithelial ovarian DG, et al. Adjuvant therapy in stage I and stage II epithelial ovarian
cancers-results of two prospective randomised trials. $N$ Engl $f$ Med cancers-results

3 Campbell S, Bhan V, Royston P, Whitehead MI, Collins WP. Transabdominal ultrasound screening for early ovarian cancer. $B M \mathcal{F}$ 1989;299:1363-7.

4 Bhan V, Amso N, Whitehead MI, Campbell S, Royston P, Collins WP. Characteristics of persistent ovarian masses in asymptomatic women. $\mathrm{Br} f$ Obstet Gynaecol 1989;96:1384-91.

5 Campbell S, Royston P, Bhan V, Whitehead MI, Collins WP. Novel screening strategies for early ovarian cancer by transabdominal ultrasonography. $\mathrm{Br} f$ Obstet Gynaecol 1990;97:304-11.

6 Van Nagell JR, Higgins RV, Donaldson ES, Gallion HH, Powell DE, Pavlik EJ, et al. Transvaginal sonography as a screening test for ovarian cancer. A report of the first 1000 cases screened. Cancer 1990;65.573-7.

7 Van Nagell JR, De Priest PD, Puls LE, Donaldson ES, Gallion HH, Pavlik $\mathrm{EJ}$, et al. Ovarian cancer screening in asymptomatic postmenopausal women EJ, et al. Ovarian cancer screening in asymptomatic
by transvaginal sonography. Cancer 1991;68:458-62.

8 Bourne TH, Campbell S, Steer C, Whitehead MI, Collins WP. Transvagina colour flow imaging: a possible new screening technique for ovarian cancer. $B M \mathcal{1}$ 1989;299:1367-70.

9 Hata K, Makihara K, Hata T, Takahashi K, Kitao M. Transvaginal color Doppler imaging for hemodynamic assessment of tumors in the reproductiv tract. Int $\mathcal{F}$ Gynecol Obstet 1991;36:301-8.

10 Kurjak A, Zalud I, Alfirevic Z. Evaluation of adnexal masses with transvagina color ultrasound. 7 Ultrasound Med 1991;10:295-7.

11 Weiner Z, Thaler I, Beck D, Rottem S, Deutsch M, Brandes J. Differentiating malignant from benign ovarian tumors with transvaginal color flow imaging. Obstet Gynecol 1992;79:159-62.

12 Kawai M, Kano T, Kikkawa F, Maedo O, Oguchi H, Tomoda Y. Transvaginal Doppler ultrasound with color flow imaging in the diagnosis of ovarian cancer. Obstet Gynecol 1992;79:163-7.

13 Booth $M$, Beral V, Smith P. Risk factors for ovarian cancer: a case-contro study. Br f Cancer 1989;60:592-8.

14 Lynch HT, Watson P, Bewtra C, Conway TA, Hippee CR, Kaur P, et al. Hereditary ovarian cancer. Cancer 1991;67:1460-6.

15 Bourne TH, Whitehead MI, Campbell S, Royston P, Bhan V, Collins WP. Ultrasound screening for familial ovarian cancer. Gynecol Oncol 1991;43 92-7.

16 Houlston RS, Collins A, Slack J, Campbell S, Collins WP, Whitehead MI et al. Genetic epidemiology of ovarian cancer: segregation analysis. Ann Hum Genet 1991;55:291-9.

17 Houlston RS, Bourne TH, Davies A, Whitehead MI, Campbell S, Collins WP, et al. Use of family history in a screening clinic for familial ovarian cancer. Gynecol Oncol 1992;42:247-52.

18 Serov SF, Scully RE, Sobin LH. International histological classification of tumors: No 9 histological typing of ovarian tumors. Geneva: World Health Organisation, 1973 .

19 Shepherd JH. Revised FIGO staging for gynaecological cancer. Br $\mathcal{J}$ Obstet Gynaecol 1989;96:889-92.

20 Collins WP, Bourne TH, Reynolds K, Bhan V, Hampson J, Royston P, et al. Ultrasound screening for early cancers. In: Sharp F, Mason WP, Creaseman $\mathrm{W}$, eds. Ovarian cancer 2: biology, investigation and management. London Chapman and Hall, 1992:225-36.

21 Campbell S, Bourne TH, Reynolds K, Hampson J, Royston P, Whitehead MI et al. Role of colour Doppler imaging in an ultrasound based screening program. In: Sharp F, Mason WP, Creaseman W, eds. Ovarian cancer 2: biology, investigation and management. London: Chapman and Hall, 1992: $237-47$

22 Granberg S, Norstom A, Wikland M. Tumors in the lower pelvis as imaged by vaginal sonography. Gynecol Oncol 1990;37:224-9.

23 Rottem S, Levit N, Thaler I, Yoffe N, Bronstein M, Manot D, et al. Classification of ovarian lesions by high-frequency transvaginal sonography. fournal of Clinical Utrasound 1990;18:359-63.

24 Sassone AM, Timor-Tritsch IE, Artner A, Westhof C, Warren WP. Transvaginal sonographic characterisation of ovarian disease: evaluation of a new scoring system to predict malignancy. Obstet Gynecol 1991;78:70-6.

25 Bourne TH, Hampson J, Reynolds K, Collins WP, Campbell S. Screening for early ovarian cancer. Br f Hosp Med 1992;48:454-9.

26 Bourne TH, Campbell S, Royston P, Whitehead MI, Steer CV, Collins WP Detection of endometrial cancer by transvaginal ultrasonography with colo flow imaging and blood flow analysis: a preliminary report. Gynecol Onco 1991;40:253-9.

(Accepted 2 March 1993) 